\title{
Synthesis and spectral studies of 5-[3-(1,2,4-triazolyl-azo]-2,4-dihydroxybenzaldehyde (TA) and its Schiff bases with 1,3-diaminopropane (TAAP) and 1,6-diaminohexane (TAAH). Their analytical application for spectrophotometric microdetermination of cobalt(II). Application in some radiochemical studies
}

\author{
Abdalla M. Khedr ${ }^{\mathrm{a}, *}$, Mohamed Gaber ${ }^{\mathrm{b}}$, Raafat M. Issa ${ }^{\mathrm{a}}$, Hasn Erten $^{\mathrm{c}}$ \\ ${ }^{a}$ Chemistry Department, Faculty of Science, Tanta University, Tanta, Egypt \\ ${ }^{\mathrm{b}}$ Chemistry Department, Faculty of Science, King Faisal University, Hofuf, Saudi Arabia \\ ${ }^{\mathrm{c} C h e m i s t r y}$ Department, Faculty of Science, Bilkent University, Bilkent, Ankara, Turkey
}

Received 25 June 2004; received in revised form 18 October 2004; accepted 10 November 2004

Available online 20 January 2005

\begin{abstract}
The new azo compound 5-[3-(1,2,4-triazolyl-azo]-2,4-dihydroxy-benzaldehyde (TA) and its Schiff bases with 1,3-diaminopropane (TAAP) and 1,6-diaminohexane (TAAH) have been synthesized. The bands of diagnostic importance in the IR and the main signals in ${ }^{1} \mathrm{H}$ NMR spectra are assigned. The electronic absorption spectra in pure organic solvents of different polarity and in buffer solutions of varying $\mathrm{pH}$ are investigated. The quantitative description of the solvent effect on the electronic absorption spectra is studied and their acid ionization constants are determined. Also, a new simple and sensitive method for the spectrophotometric microdetermination of Co(II) using these compounds (TA, TAAP and TAAH) as new chromogenic reagents is established. The developed method is successfully used for the determination of trace amounts of cobalt in authentic samples and calculation of the distribution ratio of cobalt adsorbed on bentonite and kaolinite clay minerals.
\end{abstract}

(C) 2004 Elsevier Ltd. All rights reserved.

Keywords: Azodyes; Triazole; Cobalt; Spectrophotometric determination

\section{Introduction}

The structure and absorption spectra of azo compounds, especially those containing phenolic moieties were the main subject of large research work due to their applications as textile dyes, acid-base and redox indicators, metalochromic reagents and histological

* Corresponding author. Fax: +20 403350804 .

E-mail address: abkhedr2001@yahoo.com (A.M. Khedr). stains [1-4]. Careful examination of the literature reveals that considerable work has been reported on the spectrophotometric studies of the acid-base properties of the heterocyclic azo compounds, their metal complexes and their analytical applications [5-8]. But little information has appeared in the literature concerning azo compounds derived from 3-amino-1,2,4triazole, their azo-azomethine derivatives and their metal complexes [9].

Also, cobalt possesses the radionuclide ${ }^{60} \mathrm{Co}\left(t_{1 / 2}=\right.$ $5.3 \mathrm{y})$ which has a particular importance from the 
Table 1

Physical data of ligands TA, TAAP and TAAH

\begin{tabular}{|c|c|c|c|c|c|c|}
\hline \multirow[t]{2}{*}{ Comp. } & \multirow{2}{*}{$\begin{array}{l}\text { Empirical formula } \\
\text { (formula wt.) }\end{array}$} & \multicolumn{3}{|c|}{ Microanalysis calcd. (found) } & \multirow[t]{2}{*}{ M.p. $\left({ }^{\circ} \mathrm{C}\right)$} & \multirow[t]{2}{*}{ Yield $(\%)$} \\
\hline & & $\% \mathrm{C}$ & $\% \mathrm{H}$ & $\% \mathrm{~N}$ & & \\
\hline$\overline{\mathrm{TA}}$ & $\mathrm{C}_{9} \mathrm{H}_{7} \mathrm{~N}_{5} \mathrm{O}_{3}(233.19)$ & $46.36(46.83)$ & $3.03(3.22)$ & $30.03(29.80)$ & 156 & 81 \\
\hline TAAP & $\mathrm{C}_{21} \mathrm{H}_{20} \mathrm{~N}_{12} \mathrm{O}_{4}$ (504.47) & $49.98(50.31)$ & $4.00(3.85)$ & $33.32(33.62)$ & 169 & 83 \\
\hline TAAH & $\mathrm{C}_{24} \mathrm{H}_{26} \mathrm{~N}_{12} \mathrm{O}_{4}(546.55)$ & $52.74(52.15)$ & $4.80(4.40)$ & $30.75(31.10)$ & 171 & 85 \\
\hline
\end{tabular}

radioactive waste viewpoint. ${ }^{60} \mathrm{Co}$ is an activation product that is formed from ${ }^{59} \mathrm{Co}$ is present as a component in steel used in nuclear facilities. The ${ }^{60} \mathrm{Co}$ radionuclide is also widely used in medicine to sterilize medical equipments and in cancer treatment. Due to its wide applications, relatively long half-life and intense radiation $(1332 \mathrm{keV}),{ }^{60} \mathrm{Co}$ is a radionuclide which requires safe storage and eventual disposal. In these repositories, clay minerals are used as backfilling buffering materials.

In the present article, three azo compounds based on 3-amino-1,2,4-triazole (TA, TAAP and TAAH) have been prepared, characterized and utilized as new chromogenic reagents for the spectrophotometric microdetermination of cobalt(II). Also, an attempt is done to quantify the amount of $\mathrm{Co}$ (II) ions sorbed by bentonite and kaolinite through complexation of $\mathrm{Co}(\mathrm{II})$ ions with the azo compounds that are well known to be selective and sensitive reagents for the spectrophotometric determination of $\mathrm{Co}(\mathrm{II})$ ions $[1,10-21]$ beside the routine radiotracer method [22,23].

\section{Experimental}

\subsection{Materials and methods}

All chemicals used in the present work were either of analytical grade or of high purity provided from BDH, Aldrich or Sigma. Doubly distilled water was used in all experiments.

\subsection{Preparation of the ligands}

The ligand (TA) was synthesized according to the recommended method for azo compounds [24]. This was achieved by diazotization of 3-amino-1,2,4-triazole by dissolving it in hydrochloric acid, cooling it to $0-5{ }^{\circ} \mathrm{C}$, and adding an equivalent amount of ice-cooled sodium nitrite solution with vigorous stirring. The cooled diazonium salt solution was then coupled with 2,4dihydroxybenzaldehyde. The azo compound was recrystallized from ethanol. The ligands (TAAP and TAAH) were prepared by condensation of ligand (TA) with diaminopropane or diaminohexane in stoichiometric ratio $(2: 1)$ in ethanol under reflux for $8 \mathrm{~h}$ and then recrystallized from ethanol [25]. The data of elemental analysis, empirical formulae, formula weights, melting points and reaction yields $(80-85 \%)$ of the prepared ligands are collected in Table 1.

The prepared compounds have the general structural formulae as given in Scheme 1

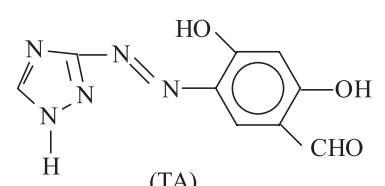

(TA)
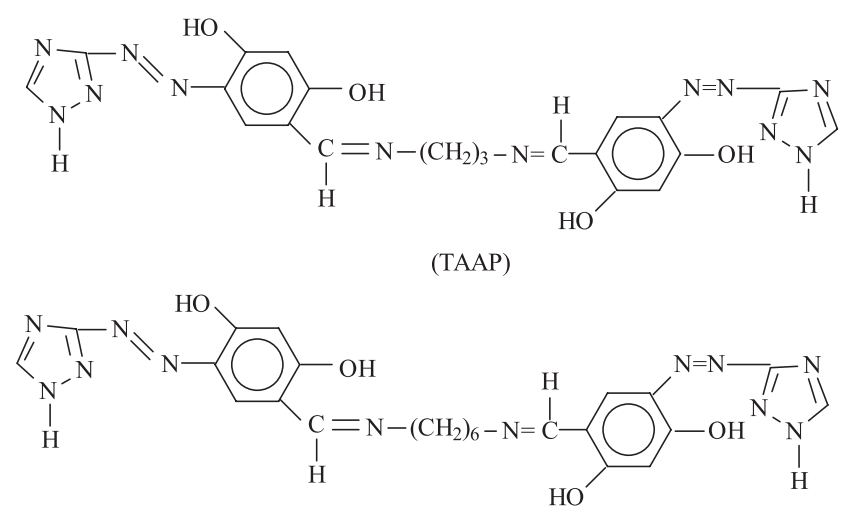

(TAAH)

Scheme 1. Structure of the ligands under investigation.

\subsection{Solutions}

$1 \times 10^{-3} \mathrm{M}$ of reagent $\mathrm{TA}$ and $5 \times 10^{-4} \mathrm{M}$ of reagents TAAP and TAAH solutions were prepared by dissolving the appropriate weight in absolute ethanol in a $100 \mathrm{ml}$ measuring flask. The stock solution of cobalt(II) was standardized by EDTA titration [26]. For the interference tests, the metal ions were obtained mostly from nitrates and some from sulfates. Solutions of the anions were prepared from their potassium or sodium salts. Universal buffer solutions of $\mathrm{pH}$ values 2-12 were prepared as recommended by Britton [27].

\subsection{Equipments}

The FTIR analysis was performed using a Bomem MB-Series instrument. The spectra of $\mathrm{KBr}$ pellets were recorded in the range $400-4000 \mathrm{~cm}^{-1}$. The ${ }^{1} \mathrm{H}$ NMR 
Table 2

Assignment of the essential peaks in the IR spectra of ligands TA, TAAP and TAAH

\begin{tabular}{|c|c|c|c|c|c|c|c|c|c|c|}
\hline Ligand & $\nu_{\mathrm{OH}}$ & $\nu_{\mathrm{NH}}$ & $\nu_{\mathrm{CH}}$ & $\nu_{\mathrm{C}=\mathrm{O}}$ & $\begin{array}{l}\nu_{\mathrm{C}=\mathrm{N}} \\
\text { (aromatic) }\end{array}$ & $\begin{array}{l}\nu_{\mathrm{C}=\mathrm{N}} \\
\text { (triaole) }\end{array}$ & $\nu_{\mathrm{N}=\mathrm{N}}$ & $\delta_{\mathrm{OH}}$ & $\nu_{\mathrm{C}-\mathrm{OH}}$ & $\delta_{\mathrm{C}-\mathrm{O}}$ \\
\hline TA & 3390 & 3122 & 3050 & 1640 & - & 1511 & 1407 & 1229 & 1164 & 1129 \\
\hline TAAP & 3438 & 3132 & 2925 & - & 1635 & 1548 & 1444 & 1222 & 1155 & 1090 \\
\hline TAAH & 3452 & 3129 & 2942 & - & 1630 & 1540 & 1452 & 1229 & 1160 & 1102 \\
\hline
\end{tabular}

spectra were carried out on a Bruker AC spectrometer operating at $300 \mathrm{MHz}$ in $d_{6}$-DMSO as a solvent using TMS as internal standard. A Cole-Parmer 5669-20-pHmeter was used in checking the $\mathrm{pH}$-values of the universal buffer solutions. The UV/Vis absorption spectra were recorded using a Cary-5E-UV-NIR spectrophotometer. The blank used was the organic solvent, buffer solution or the buffer solution containing the same concentration of the ligand as that in the test solution in case of the determination of $\mathrm{Co}(\mathrm{II})$.

\subsection{Recommended procedure for the spectrophotometric determination of cobalt(II)}

To a definite volume of the sample solution containing $1-5 \mathrm{ppm}$ of $\mathrm{Co}(\mathrm{II}), 4 \mathrm{ml}$ of reagent $\left[1 \times 10^{-3} \mathrm{M}\right.$ (TA) or $5 \times 10^{-4} \mathrm{M}$ (TAAH)], $5 \mathrm{ml}$ universal buffer solution of $\mathrm{pH} 8.0$ or 11.0 (for TA or TAAH, respectively) were added and completed to the mark with doubly distilled water in a $10 \mathrm{ml}$ measuring flask. The solutions were thoroughly mixed and the mixture was allowed to stand for $5 \mathrm{~min}$. The absorbance at 535 and $555 \mathrm{~nm}$ was measured against a reference blank solution prepared in the same manner from TA and TAAH, respectively. The calibration graphs were constructed by plotting the absorbance vs $\mathrm{Co}$ (II) content (ten points in the range $1-5 \mathrm{ppm}$ of $\mathrm{Co}(\mathrm{II})$; the plots were linear passing through the origin).

\subsection{Recommended procedure for the} spectrophotometric determination of the distribution ratio of cobalt on bentonite and kaolinite

The natural clay mineral samples of kaolinite and bentonite were obtained from the Turkish General Directorate of Mineral Research and Exploration (MTA). The sorption experiments were carried out by mixing $50.0 \mathrm{ml}$ aliquots of $1.0 \times 10^{-2}, 1.0 \times 10^{-3}$, $1.0 \times 10^{-4}, 1.0 \times 10^{-5} \mathrm{M}$ of $\mathrm{Co}(\mathrm{II})$ solutions with kaolinite and bentonite samples weighing $0.50 \mathrm{~g}$ of each clay mineral for $48 \mathrm{~h}$ using a magnetic stirrer. The samples were then filtrated and the filtrate was used for the spectrophotometric determination of its $\mathrm{Co}(\mathrm{II})$ content using the procedure developed in the present work and the radiotracer method [22,23].

\section{Results and discussion}

\subsection{The IR spectra}

The wavenumbers of some characteristic bands in the IR spectra of ligands TA, TAAP and TAAAH are listed in Table 2 and interpreted in the light of molecular structure. The IR spectra of all compounds exhibited broad bands within the range $3390-3452 \mathrm{~cm}^{-1}$ corresponding to the stretching vibration of $\mathrm{OH}$ groups. The low values of $\nu_{\mathrm{OH}}$ reflects the existence of intramolecular hydrogen bonds between $\mathrm{OH}$ and $\mathrm{N}=\mathrm{N}$ or $\mathrm{C}=\mathrm{N}$ groups [28]. The NH stretching bands of the triazole ring are found within the range $3122-3132 \mathrm{~cm}^{-1}$. The IR spectrum of ligand TA exhibits band at $1640 \mathrm{~cm}^{-1}$ corresponding to the stretching vibration of the formyl $\mathrm{C}=\mathrm{O}$ group. The stretching mode of the Schiff base $\mathrm{C}=\mathrm{N}$ group of ligands TAAP and TAAH leads to the bands at 1630 and $1635 \mathrm{~cm}^{-1}$. The stretching modes of $\mathrm{C}=\mathrm{N}$ groups of the triazole moiety give bands at $1511-1548 \mathrm{~cm}^{-1}$ while the $\mathrm{N}=\mathrm{N}$ bands give $\nu_{\mathrm{N}=\mathrm{N}}$ (symmetrical) at $1407-1452 \mathrm{~cm}^{-1}$. The asymmetrical $\mathrm{N}=\mathrm{N}$ band usually overlaps with the bands of the aromatic rings and hence is difficult to identify [29]. The IR spectra of the compounds under investigation exhibited medium or strong peaks within the range $1222-1229 \mathrm{~cm}^{-1}$ due to $\delta_{\mathrm{OH}}$ mode while the weak intensity bands within $1155-1164$ and $1090-1129 \mathrm{~cm}^{-1}$ are assigned to $\nu_{\mathrm{C}-\mathrm{OH}}$ and $\delta_{\mathrm{C}-\mathrm{O}}$ vibrations, respectively [28].

\section{2. ${ }^{1} H$ NMR spectra}

The ${ }^{1} \mathrm{H}$ NMR spectrum of the ligand (TA) displayed the presence of the broad singlet signal due to the hydrogen of CHO group at $\delta 10.958 \mathrm{ppm}$ which is lower field shifted to $\delta 8.39$ and 8.60 in the spectra of the ligands TAAP and TAAH through Schiff base formation. On the other hand, the spectra of the ligands TAAP

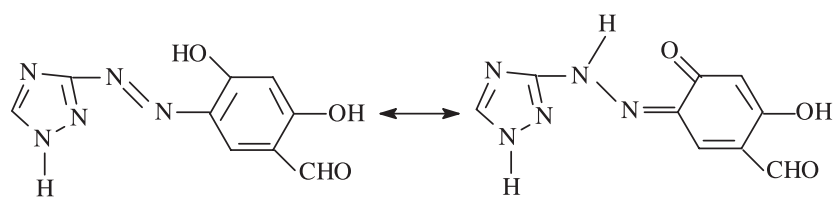

Scheme 2. Keto-enol toutmerism in ligand TA. 
Table 3

${ }^{1}$ H NMR spectral data of TA, TAAP and TAAH

\begin{tabular}{llll}
\hline \multicolumn{2}{l}{ Compound number } & \multicolumn{2}{l}{ Assignment } \\
\cline { 1 - 3 } TA & TAAP & TAAH & \\
\hline 2.52 & 2.51 & 2.53 & $\mathrm{NH}$ (heterocyclic ring) \\
- & 3.33 & 3.29 & $\left(\mathrm{CH}_{2}\right)$ \\
6.38 & 6.36 & 6.37 & $\mathrm{NH}$ (tout) \\
$7.51-7.55$ & $7.19-7.46$ & $7.51-7.56$ & $\mathrm{Ar} \mathrm{H}$ \\
- & 8.39 & 8.60 & $\mathrm{CH}=\mathrm{N}$ \\
9.92 & - & - & $\mathrm{CH}=\mathrm{O}$ \\
10.15 & 9.74 & 9.92 & $\mathrm{OH}$ \\
\hline
\end{tabular}

and TAAH showed multiplet signals at $\delta 3.33$ and $3.29 \mathrm{ppm}$ due to the hydrogens of the methylene groups of the Schiff base [30]. The spectra of the ligands TA, TAAP and TAAH exhibited multiplet signals at $\delta 7.51-7.55,7.19-7.46$ and $7.51-7.56 \mathrm{ppm}$, respectively, integrated for the aromatic hydrogens of the phenyl and triazole rings. Also, the two strong signals appearing in the $\delta$ ranges $6.36-6.38$ and $9.74-10.15 \mathrm{ppm}$ can be attributed to the hydrogens of both $\mathrm{NH}$ of the hydrazone species (Scheme 2) and OH groups, respectively [30]. The data obtained from ${ }^{1} \mathrm{H}$ NMR spectra of the investigated ligands are collected in Table 3.

\subsection{The electronic absorption spectra of the free} ligands (TA, TAAP and TAAH) in organic solvents of different polarity

\subsubsection{Band assignment}

The electronic absorption spectra of the investigated dyes have been studied in 15 organic solvents of different polarity namely methanol, ethanol, $n$-butanol, $t$-butylalkhol, DMF, DMSO, cyclohexane, xylene, $n$-hexane, carbontetrachloride, toluene, methylene chloride, chloroform and dioxane. The UV/Vis absorption spectra of the free ligands (TA, TAAP and TAAH) in organic solvents of different polarity display mainly four bands. The first band located at $275-293 \mathrm{~nm}$ can be assigned to the moderate energy $\left(\pi-\pi^{*}\right)$ transition of the aromatic ring $\left({ }^{1} \mathrm{~L}_{\mathrm{a}}-{ }^{1} \mathrm{~A}\right)[31]$ while the second band at $307-357 \mathrm{~nm}$ is due to low energy $\left(\pi-\pi^{*}\right)$ transition corresponding to the $\left({ }^{1} \mathrm{~L}_{\mathrm{b}}-{ }^{1} \mathrm{~A}\right)$ state [31]. The third band located at $360-400 \mathrm{~nm}$ corresponds to $\left(\pi-\pi^{*}\right)$ transition involving the $\pi$-electrons of the azo and azomethine groups [32]. The very broad band observed in the range $500-576 \mathrm{~nm}$ can be assigned to an intramolecular charge transfer interaction involving the whole molecule. The strong broadness of the intermolecular CT band can be assigned to the existence of azo-hydrazone toutmeric equilibrium originating from the $\mathrm{OH}$ group in $o$-position to the $\mathrm{N}=\mathrm{N}$ center [33] which can be represented as given in Scheme 2.

Thus the CT band can be considered as a composite band resulting from the absorption of the two equilibrium species. The absorption region on the lower energy site would be due to the hydroxy-azo form while that at higher energy region can be attributed to the absorption by the $o$-quinone hydrazone species [34,35]. This behaviour seems to be quite common for azo or azomethine dyes having a hydroxy group in $o$-position to the $\mathrm{N}=\mathrm{N}$ or $\mathrm{C}=\mathrm{N}$ bond on the aromatic ring.

The low excitation energy of this transition in the case of the hydrazo species relative to the corresponding one in the azo form is presumably due to the quinoid structure of the former isomer which is expected to facilitate such a type of transition [34].

\subsubsection{Solvatochromic behaviour}

The electronic absorption spectra of the free ligands TA, TAAP and TAAH were investigated in organic solvents of different polarity. The results obtained indicate that the UV $\left(\pi-\pi^{*}\right)$ bands with relative high extinction coefficient suffer small solvent shifts, a behaviour which is characteristic of this type of electronic transitions. Also, the data revealed that the intramolecular CT band appearing in the range $500-576 \mathrm{~nm}$ exhibited a red shift on changing the solvent in the direction; cyclohexane, $n$-hexane, carbontetrachloride, xylene, toluene, methylene chloride, chloroform, dioxane, methanol, ethanol, $n$-butanol, $t$-butylalkhol, DMF and DMSO. This trend is in harmony with increasing polarity of the solvent. This can be explained on the principle that the excited state being more polar than the ground state will be more stabilized in polar solvents. Therefore, lower excitation energy is required for the CT transition in the polar solvents relative to the lower polarity ones. On the other hand, the bands due to $\mathrm{N}=\mathrm{N}$ and $\mathrm{C}=\mathrm{N}$ groups exhibit a blue shift in methanol and ethanol relative to DMF and DMSO. This can be ascribed to the difficult excitation of the electrons of the azo and azomethine groups in methanol and ethanol due to locking of their n-electrons by methanol and ethanol molecules via hydrogen bonds, this also causes a weaker intramolecular hydrogen bond in solvated molecule hence the blue shift was observed $[35,36]$.

\subsection{The electronic absorption spectra of the free ligands (TA, TAAP and TAAH) in buffer solutions of different $p H$ values and spectrophotometric determination of their dissociation constants $\left(p K_{1}\right.$ and $\left.p K_{2}\right)$}

In the light of previous studies of the acid-base properties of azo compounds containing a heterocyclic ring with $\mathrm{NH}$ group [37] ligand TA is to be considered as a tribasic acid while TAAP and TAAH would be hexabasic acids. The dissociation of these acids can be represented by the following equilibria (Scheme 3):

The absorption spectra of the ligands TA, TAAP and TAAH in $10 \%$ ethanol universal buffer solutions of $\mathrm{pH}$ 


$$
\begin{aligned}
& \mathrm{H}_{3} \mathrm{~L} \underset{\mathrm{K}_{1}}{\rightleftharpoons} \mathrm{H}_{2} \mathrm{~L}^{-}+\mathrm{H}^{+}, \mathrm{H}_{2} \mathrm{~L}-\stackrel{\mathrm{K}_{2}}{\rightleftharpoons} \mathrm{HL}^{2-}+\mathrm{H}^{+} \text {and } \mathrm{HL}^{2-} \stackrel{\mathrm{K} 3}{\rightleftharpoons} \mathrm{L}^{3-}+\mathrm{H}^{+} \longrightarrow \text { (1) } \\
& \mathrm{H}_{6} \mathrm{~L} \underset{\mathrm{K}_{1}}{\rightleftharpoons} \mathrm{H}_{4} \mathrm{~L}^{2-}+2 \mathrm{H}^{+}, \mathrm{H}_{4} \mathrm{~L}^{2-} \stackrel{\mathrm{K}_{2}}{\rightleftharpoons} \mathrm{H}_{2} \mathrm{~L}^{4-}+2 \mathrm{H}^{+} \text {and } \mathrm{H}_{2} \mathrm{~L}^{4-} \stackrel{\mathrm{K} 3}{\rightleftharpoons} \mathrm{L}^{6-}+2 \mathrm{H}^{+} \longrightarrow \text { (2) } \\
& \quad \text { where } \mathrm{K}_{1}, \mathrm{~K}_{2} \text { and } \mathrm{K}_{3} \text { are the dissociation constants for each step. }
\end{aligned}
$$

Scheme 3. The acid-base equilibrium of the ligands under study.

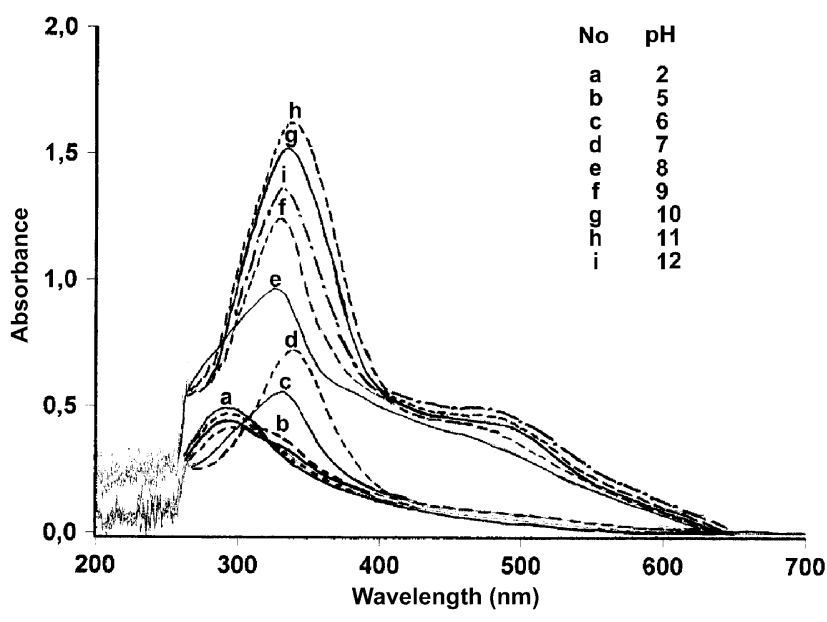

Fig. 1. The electronic absorption spectra of ligand (TAAH) in buffer solution of different $\mathrm{pH}$ values.

2-12 were investigated in the $\mathrm{UV} / \mathrm{Vis}$ region $(200-600 \mathrm{~nm})$. The spectra obtained indicate that the absorbance and position of the absorption bands changed with $\mathrm{pH}$ of the medium according to the following:

1. In case of ligand TA; in solution having $\mathrm{pH}<5$, the absorption spectra showed an absorption peak with

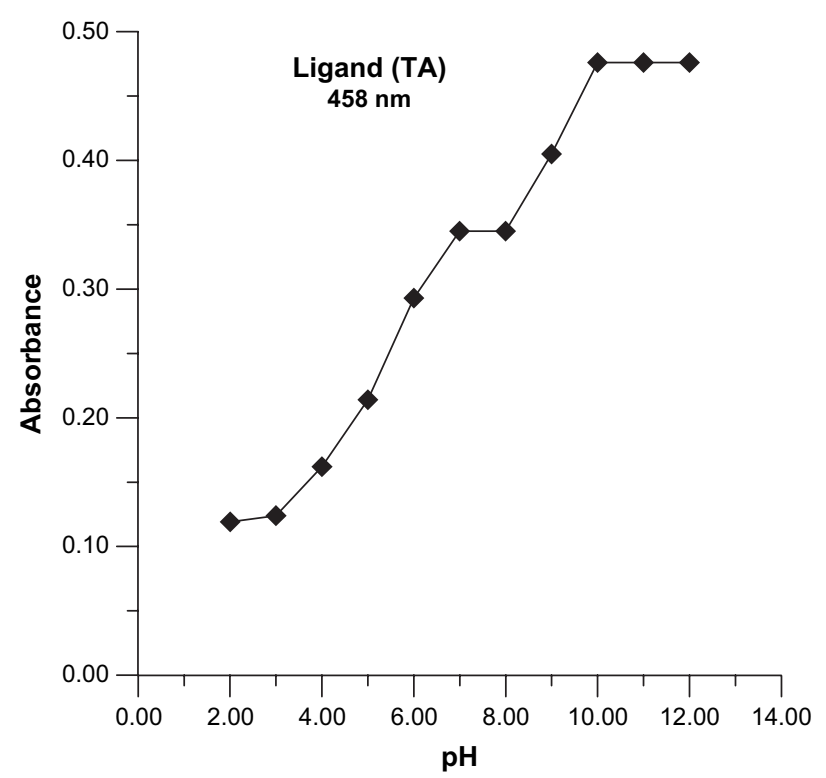

Fig. 2. The pH-absorbance curve of ligand (TA). $\lambda_{\max }=280 \mathrm{~nm}$ (band I) corresponding to $\mathrm{H}_{3} \mathrm{~L}$ form, the extinction of this peak decreases with increasing $\mathrm{pH}$ values of solution while another absorption peak appeared at $\mathrm{pH} \geq 5$ with $\lambda_{\max }=330 \mathrm{~nm}$ (band II) corresponding to the $\mathrm{H}_{2} \mathrm{~L}^{-}$form. The absorbance of this peak increases with increasing $\mathrm{pH}$-value of the solution until $\mathrm{pH}=10$. A third band appeared at $\mathrm{pH}>7$ with $\lambda_{\max }=458 \mathrm{~nm}$ (band III) corresponding to $\mathrm{HL}^{2-}$ and $\mathrm{L}^{3-}$ forms, the extinction of this peak increases with increasing $\mathrm{pH}$ values of the solution until $\mathrm{pH}=12$. So one can conclude that, in solution of $\mathrm{pH}<7$, TA exists essentially as undissociated molecules, whereas at higher $\mathrm{pH}$ values the dissociated forms predominate. Since each species has a characteristic band, the absorbance of these bands can be taken as a measure of the concentration of each form.

2. The spectra of ligand TAAP showed three different peaks with $\lambda_{\max }$ equals 288,340 and $500 \mathrm{~nm}$ corresponding to $\mathrm{H}_{6} \mathrm{~L}, \mathrm{H}_{4} \mathrm{~L}^{2-}$ and $\mathrm{H}_{2} \mathrm{~L}^{-4}$ forms, respectively. The extinction of the first peak of the undissociated form decreases with increasing $\mathrm{pH}$ of solution, while the absorbance of the second and the third peaks of the dissociated form increases with increasing $\mathrm{pH}$ values.

The changes of absorbance with $\mathrm{pH}$ of the solution lead to the appearance of isosbestic points

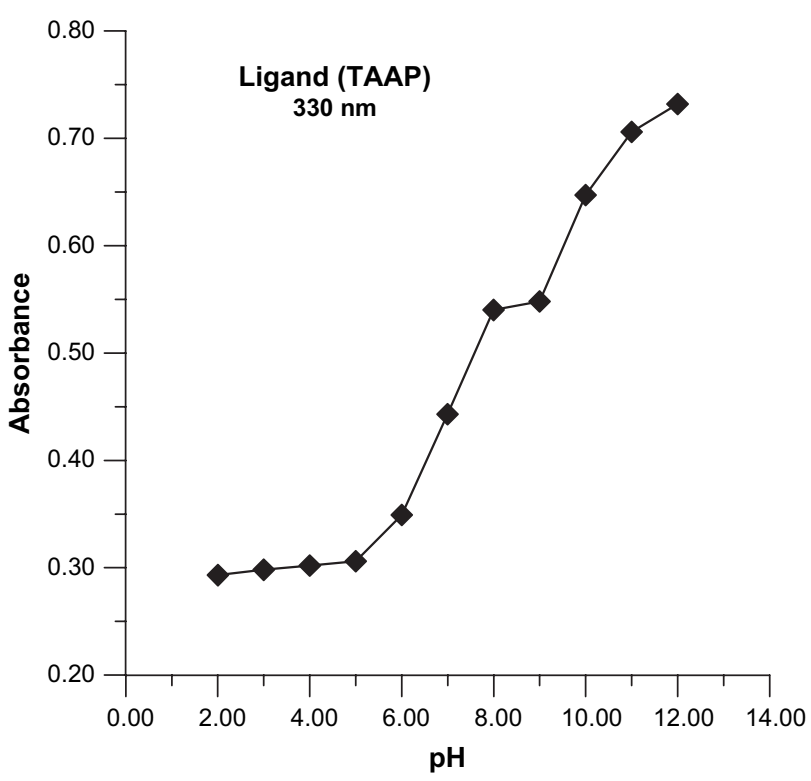

Fig. 3. The $\mathrm{pH}-$ absorbance curve of ligand (TAAP). 


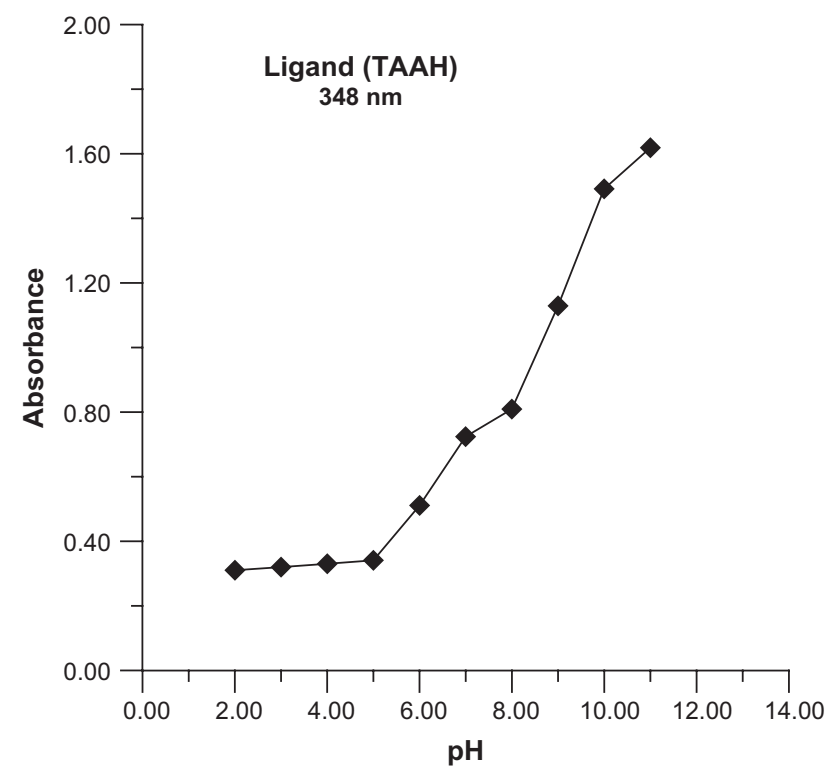

Fig. 4. The pH-absorbance curve of ligand (TAAH).

at $\lambda=304$ and $308 \mathrm{~nm}$ for both ligands $\mathrm{TA}$ and TAAP, respectively, indicating the existence of an acid-base equilibrium between two different forms of these compounds as given above.

3. The spectra of ligand TAAH (Fig. 1) showed three peaks with $\lambda_{\max }$ equals 292, 348 and $475 \mathrm{~nm}$ corresponding to $\mathrm{H}_{6} \mathrm{~L}, \mathrm{H}_{4} \mathrm{~L}^{-2}$ and $\mathrm{H}_{2} \mathrm{~L}^{-4}$ forms, respectively. The extinction of the first band due to undissociated form decreases with increasing $\mathrm{pH}$ and this band disappeared at $\mathrm{pH}>5$, while the extinction of both the second and third bands due to the ionic forms increased with increasing $\mathrm{pH}$.

The spectra of ligands TAAP and TAAH indicate that each two identical protons from both sides of the molecules are liberated in one step, which may be ascribed to strong similarity between each two identical protons. The $\mathrm{pH}-$ absorbance curves of the investigated compounds showed two inflections due to the two ionization steps (Figs. 2-4). The existence of two steps in the $\mathrm{pH}$-absorbance curves denotes only two types of equilibria. Thus, it is possible to consider that the second and third ionization steps will overlap together in one step. These curves were utilized for the determination of

Table 4

The values of $\mathrm{p} K_{1}$ and $\mathrm{p} K_{2}$ for ligands TA, TAAP and TAAH

\begin{tabular}{|c|c|c|c|c|c|c|c|}
\hline \multirow[t]{2}{*}{ Ligand } & \multirow{2}{*}{$\begin{array}{l}\lambda \\
(\mathrm{nm})\end{array}$} & \multicolumn{3}{|l|}{$\mathrm{p} K_{1}$} & \multicolumn{3}{|l|}{$\mathrm{p} K_{2}$} \\
\hline & & H.H.M & L.A.M & Av.V. & H.H.M & L.A.M & Av.V. \\
\hline TA & 458 & 5.2 & 5.4 & 5.3 & 9.1 & 9.3 & 9.2 \\
\hline TAAP & 330 & 6.69 & 6.8 & 6.75 & 9.88 & 9.98 & 9.93 \\
\hline TAAH & 348 & 6.24 & 6.44 & 6.34 & 9.15 & 9.35 & 9.25 \\
\hline
\end{tabular}

the two acid dissociation constants of these ligands applying the half-height [38] and the limiting absorbance methods [39]. The values of $\mathrm{p} K_{1}$ and $\mathrm{p} K_{2} \quad\left(\mathrm{p} K_{2}\right.$ overlapping with $\mathrm{p} K_{3}$ ) obtained from half-height and limiting absorbance methods are listed in Table 4.

\subsection{Analytical studies}

\subsubsection{Optimization}

On mixing the ligands under investigation and $\mathrm{Co}(\mathrm{II})$ ion, red colours are observed in contrast to their original yellow colours. The absorption spectra of the Co(II)-complexes with ligands TA, TAAP and TAAH were studied at different $\mathrm{pH}$ values using universal buffer solutions. The evaluation of the optimum conditions for the determination of cobalt(II) resulted from a careful investigation of all factors involved in the procedures.

\subsubsection{Effect of $p H$ and selection of the suitable wavelength}

The absorption spectra of $\mathrm{Co}(\mathrm{II})$-complexes with ligands TA, TAAP and TAAH were investigated in buffer solutions of $\mathrm{pH} 2.0-12.00$. The same amounts of ligand and buffer were used as a blank. The optimum $\mathrm{pH}$ values are 8 for ligand TA and 11 for ligands TAAP and TAAH. The absorption spectra of the formed complexes exhibited one broad band which was shifted

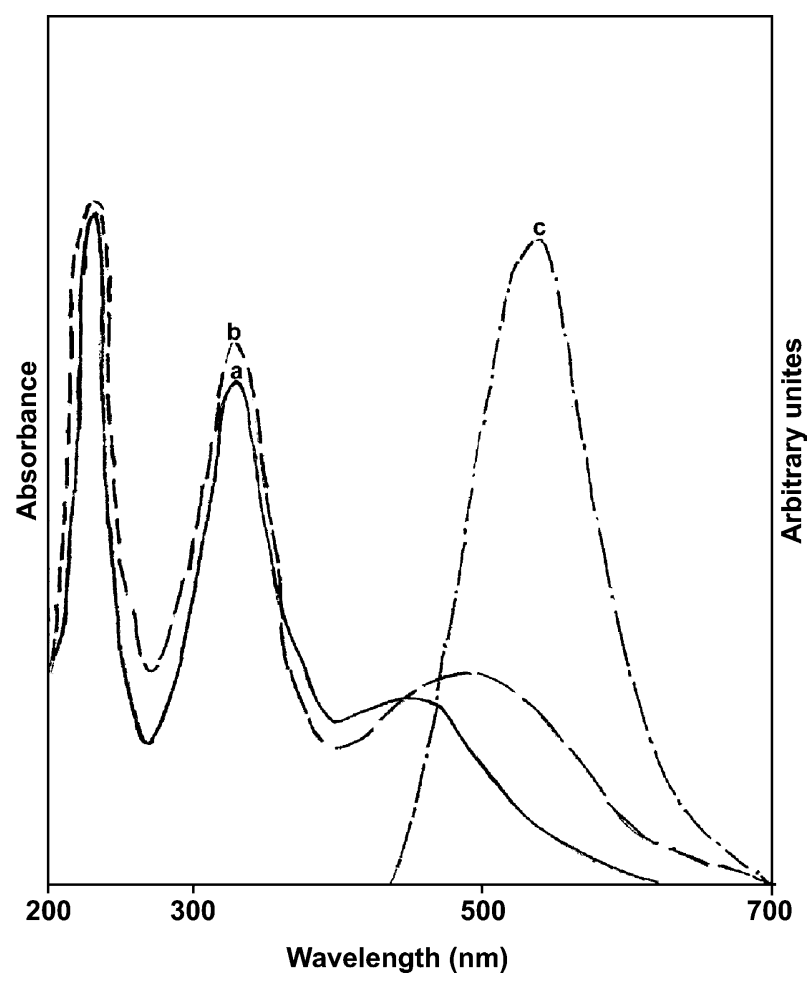

Fig. 5. The electronic absorption spectra of ligand (TA) and its $\mathrm{Co}$ (II)-complexes at the recommended $\mathrm{pH}$ values. (a) Ligand against methanol and buffer as a reference, (b) $\mathrm{Co}(\mathrm{II})$-complex against methanol and buffer as a reference, (c) $\mathrm{Co}$ (II)-complex against ligand, methanol and buffer as a reference. 
to longer wavelength with increasing $\mathrm{pH}$. The $\mathrm{Co}(\mathrm{II})$ TA, -TAAP and -TAAH complexes showed maximum absorbance at 535, 530 and $555 \mathrm{~nm}$, respectively. The absorption bands were shifted to longer wavelength in case of $\mathrm{Co}(\mathrm{II})$-complexes compared to that of the free ligands (Fig. 5). This shift of $\lambda_{\max }$ of the complexes to longer wavelengths can be attributed to increased delocalization of the electrons on complexation leading to a decrease in the energy gap between the ground and the excited states $[40,41]$.

\subsubsection{Effect of sequence of addition and organic solvent ratio}

The sequence (ligand-metal-buffer) was found to be the best one for the formation of $\mathrm{Co}(\mathrm{II})$-chelate with TA whereas the sequence (metal-buffer-ligand) is the best one for the formation of $\mathrm{Co}$ (II)-chelate with TAAP and TAAH. The effect of organic solvent ratio showed that the colour of complexes attained a maximum value at a ratio of $40 \%(\mathrm{v} / \mathrm{v})$ ethanol.

\subsubsection{Effect of time and temperature}

The colours of complexes are formed instantaneously and are stable for more than $24 \mathrm{~h}$. Temperature exhibits no obvious influence on colour development.

\subsubsection{Effect of reagent concentration}

The effect of reagent concentration on the intensity of the colour of the complexes was investigated by varying the reagent concentration under the optimum conditions. The results indicated that the suitable reagent concentration is $4 \times 10^{-4} \mathrm{M}$ in case of TA and $2 \times 10^{-4} \mathrm{M}$ in cases of TAAP and TAAH.

\subsubsection{Stoichiometry of the complexes}

The composition of the Co(II)-complexes with each of the reagents was established by the continuous variation [42] and mole ratio [43] methods which revealed the formation of $1: 1$ and $1: 2(\mathrm{M}: \mathrm{L})$ complexes with TA and formation of 1:1 and 2:1 (M:L) complexes with TAAP and TAAH. The conditional stability constants and the free energy change $\left(\Delta G^{*}\right)$ of formation of the $\mathrm{Co}(\mathrm{II})$-complexes with TA, TAAP and TAAH were calculated using the results of mole ratio and continuous variation methods [44] and are given in Table 5. The values obtained showed that the stability of the complexes increased with increasing the number of ligand molecules attached to the metal ion.

\subsubsection{Effect of foreign ions}

The possible interference of various ions was examined by introducing them into a solution containing $\left(3 \times 10^{-5} \mathrm{M}\right)$ of cobalt(II). The data led to the conclusion that $\mathrm{Na}^{+}, \mathrm{K}^{+}, \mathrm{Mg}^{+2}, \mathrm{Ca}^{+2}, \mathrm{Ba}^{+2}, \mathrm{Sr}^{+2}$, $\mathrm{Al}^{+3}, \mathrm{CO}_{3}^{-2}, \mathrm{PO}_{4}^{-3}, \mathrm{SO}_{4}^{-2}, \mathrm{Cl}^{-}, \mathrm{Br}^{-}$and $\mathrm{CH}_{3} \mathrm{COO}^{-}$ions did not interfere. On the other hand $\mathrm{Co}^{+3}, \mathrm{Cu}^{+2}, \mathrm{Fe}^{+2}$, $\mathrm{Pb}^{+2}, \mathrm{Ni}^{+2}$ and $\mathrm{Cd}^{+2}$ ions caused a positive deviation due to their ability to form coloured complexes with the excess of ligands, the absorbance of which overlaps with that of the $\mathrm{Co}(\mathrm{II})$-complexes. $\mathrm{CN}^{-}, \mathrm{SCN}^{-}$and $\mathrm{EDTA}^{-2}$ ions exhibited negative deviation based on their tendency to form complexes with $\mathrm{Co}(\mathrm{II})$ ions.

\subsubsection{Beer's law and sensitivity}

The ranges of linearity (Table 5) of absorbance as a function of $\mathrm{Co}$ (II) concentration i.e. obeyance to Beer's law, provide a satisfactory measure of the sensitivity of each ligand. For more accurate results, Ringbom [45] optimum concentration range was determined by plotting log [Co(II)] in ppm against percent transmittance and the linear portion of the $\mathrm{Z}$-shaped curve gives the accurate range of analysis (Table 5). It can be seen that the Co(II)-TA system is the most sensitive, since its molar absorptivity is the highest $\left(2.0456 \times 10^{4} 1 \mathrm{~mol}^{-1} \mathrm{~cm}^{-1}\right)$ compared with that of Co(II)-TAAH system $\left(1.8565 \times 10^{4} 1 \mathrm{~mol}^{-1} \mathrm{~cm}^{-1}\right)$. On the other hand, Co(II)-TAAP system is the least sensitive for $\mathrm{Co}(\mathrm{II})$ determination due to its low molar absorptivity $\left(0.1349 \times 10^{4} 1 \mathrm{~mol}^{-1} \mathrm{~cm}^{-1}\right)$. The specific absorptivities $\left(a, \mathrm{ml} \mathrm{g}^{-1} \mathrm{~cm}^{-1}\right)$, Sandell sensitivities (S.S) $\left(\mathrm{g} / \mathrm{cm}^{2}\right)$, standard deviations (S.D) and correlation coefficients (C.C) for each reagent were calculated and summarized in Table 5. It was found that, the standard deviations are small and the correlation coefficients are

Table 5

Electronic absorption spectral data of $\mathrm{Co}^{2+}$-chelates with ligands TA, TAAP and TAAH

\begin{tabular}{lcclrrrrrrrrr}
\hline Ligand & $\mathrm{pH}$ & $\lambda_{\max }$ & Molar ratio & $\log \beta_{n}$ & \multicolumn{1}{c}{$\Delta G^{*}$} & Beer's Up to & $\varepsilon$ & \multicolumn{1}{l}{$a$} & S.S & C.C & S.D & Ringbom (ppm) \\
\hline TA & 8.0 & 535 & $1: 1$ & 3.6445 & 5.0020 & $4.1251(\mathrm{ppm})$ & 20456 & 0.3470 & 0.0029 & 0.9998 & 0.0094 & $0.89-3.28$ \\
& & & $1: 2$ & 7.4200 & 10.1845 & & & & & & & \\
TAAP & 11.0 & 530 & $1: 1$ & 2.0120 & 2.9101 & $2.0626(\mathrm{ppm})$ & 18565 & 0.3150 & 0.0032 & 0.9993 & 0.1099 & $0.94-2.46$ \\
& & & $1: 2$ & 4.2090 & 5.7772 & & & & & & & \\
TAAH & \multirow{2}{*}{11.0} & 555 & $1: 1$ & 1.0870 & 1.4923 & $11.787(\mathrm{ppm})$ & 1349 & 0.0229 & 0.0437 & 0.9998 & 0.0077 & $1.20-8.18$ \\
& & & $1: 2$ & 1.5989 & 2.1946 & & & & & & &
\end{tabular}

$\log \beta_{n}$ : Log stability constant. $-\Delta G^{*}$ : Free energy change (K Cal $\left./ \mathrm{mol}\right) . \varepsilon$ : Molar extinction coefficient $\left(1 \mathrm{~mol}^{-1} \mathrm{~cm}^{-1}\right) . a$ : Specific absorptivity $\left(\mathrm{ml} \mathrm{g}^{-1} \mathrm{~cm}^{-1}\right)$. S.S: Sandell's sensitivity $\left(\mu \mathrm{g} / \mathrm{cm}^{2}\right)$. C.C: Correlation coefficient. S.D: Standard deviation. 
Table 6

Sorption of $\mathrm{Co}^{2+}$ ions on bentonite

\begin{tabular}{|c|c|c|c|c|}
\hline$[C]^{\mathrm{o}}$ & {$\left[C_{\mathrm{L}}\right]$} & {$\left[C_{\mathrm{s}}\right]$} & $R_{\mathrm{d}}$ & $\%$ Sorption \\
\hline \multicolumn{5}{|c|}{ (A) Results obtained by spectrophotometric method using ligand TA } \\
\hline $1 \times 10^{-2}$ & $163 \times 10^{-5}\left(171 \times 10^{-5}\right)$ & $837 \times 10^{-3}\left(829 \times 10^{-3}\right)$ & $513(508)$ & $83.7(82.9)$ \\
\hline $1 \times 10^{-3}$ & $16 \times 10^{-5}\left(16 \times 10^{-5}\right)$ & $84 \times 10^{-3}\left(84 \times 10^{-3}\right)$ & $525(525)$ & $84.0(84.0)$ \\
\hline $1 \times 10^{-4}$ & $11 \times 10^{-6}\left(11 \times 10^{-6}\right)$ & $89 \times 10^{-4}\left(89 \times 10^{-4}\right)$ & $809(809)$ & $89.0(89.0)$ \\
\hline $1 \times 10^{-5}$ & $23 \times 10^{-7}(-)$ & $77 \times 10^{-5}(-)$ & $\underline{335}(-)$ & $\underline{77.0}(-)$ \\
\hline \multicolumn{5}{|c|}{ (B) Results obtained using radiotracer method } \\
\hline $1 \times 10^{-3}$ & $18 \times 10^{-5}$ & $82 \times 10^{-3}$ & 456 & 82.0 \\
\hline $1 \times 10^{-4}$ & $13 \times 10^{-6}$ & $87 \times 10^{-4}$ & 669 & 87.0 \\
\hline $1 \times 10^{-5}$ & $93 \times 10^{-8}$ & $91 \times 10^{-5}$ & 975 & 90.7 \\
\hline $1 \times 10^{-6}$ & $8 \times 10^{-8}$ & $92 \times 10^{-6}$ & 1150 & 92.0 \\
\hline
\end{tabular}

The values in the parentheses indicate results obtained using ligand TAAH. $[C]^{\circ}$ is the initial concentration of Co(II) ions (meq/ml) used in the sorption experiment. [ $\left.C_{\mathrm{s}}\right]$ is the equilibrium concentration of $\mathrm{Co}(\mathrm{II})$ ions on the solid phase (mmol/g) at the end of the sorption experiment. $\left[C_{\mathrm{L}}\right]$ is the equilibrium concentration of $\mathrm{Co}(\mathrm{II})$ ions on the liquid phase $(\mathrm{mmol} / \mathrm{ml})$ after the sorption experiment. $R_{\mathrm{d}}$ is the distribution ratio of $\mathrm{Co}(\mathrm{II})$ ions between the solid and liquid phase.

close to unity confirming the possible application of the method for the spectrophotometric microdetermination of cobalt(II) as a simple, accurate and fast method.

\subsubsection{Application and reproducibility}

In order to determine the accuracy and precision of the developed method, the present method had been applied for the determination of cobalt(II) in authentic mixtures prepared by mixing small quantities of $\mathrm{Mg}^{2+}$, $\mathrm{Pb}^{2+}, \mathrm{Al}^{3+}$ and $\mathrm{Ca}^{2+}$ (sulfate salts) with a known concentration of $\mathrm{Co}(\mathrm{II})$ using TA and TAAH as chromogenic reagents.

The reproducibility of results was checked by eight replicate analysis of a solution containing 2.15095 and $1.29646 \mathrm{mg} / \mathrm{l}$ of cobalt(II) using TA and TAAH as chromogenic reagents. The standard deviation was 0.0051 and 0.0046 and the percentage recovery of spiked sample was 99.46 and $99.01 \%$ for Co(II) ions using TA and TAAH, respectively.

\subsubsection{Spectrophotometric determination of the distribution ratio of cobalt on bentonite and kaolinite}

In sorption studies, the distribution ratio $\left(R_{\mathrm{d}}\right)$ aids in quantifying the extent of retardation of a certain trace element transported via an aqueous phase by a solid phase. $R_{\mathrm{d}}$ is an empirical value that is used to quantify the extent of retardation of a certain trace element by a solid phase from solution under certain conditions. It is a measure of the ratio of the amount of the element bound to the solid phase $\left[C_{\mathrm{s}}\right]$ relative to that in the liquid phase $\left[C_{\mathrm{L}}\right]$ at equilibrium, i.e.:

$R_{\mathrm{d}}=\left[C_{\mathrm{s}}\right] /\left[C_{\mathrm{L}}\right]$

For the experiments carried out using the radiotracer method [22,23], $R_{\mathrm{d}}$ can be calculated based on the changes in activity of the liquid phase according to the equation:

$R_{\mathrm{d}}=V A^{\mathrm{o}}-V A_{\mathrm{L}} / A_{\mathrm{L}} W_{\mathrm{s}}$

Table 7

Sorption of $\mathrm{Co}^{2+}$ ions on kaolinite

\begin{tabular}{|c|c|c|c|c|}
\hline$\underline{[C]^{\circ}}$ & {$\left[C_{\mathrm{L}}\right]$} & {$\left[C_{\mathrm{s}}\right]$} & $R_{\mathrm{d}}$ & $\%$ Sorption \\
\hline \multicolumn{5}{|c|}{ (A) Results obtained by spectrophotometric method using ligand TA } \\
\hline $1 \times 10^{-2}$ & $52 \times 10^{-4}\left(51 \times 10^{-4}\right)$ & $48 \times 10^{-2}\left(49 \times 10^{-2}\right)$ & $92(94)$ & $48.0(49.0)$ \\
\hline $1 \times 10^{-3}$ & $46 \times 10^{-5}\left(46 \times 10^{-5}\right)$ & $54 \times 10^{-3}\left(54 \times 10^{-3}\right)$ & $117(117)$ & $54.0(54.0)$ \\
\hline $1 \times 10^{-4}$ & $35 \times 10^{-6}\left(34 \times 10^{-6}\right)$ & $65 \times 10^{-4}\left(66 \times 10^{-4}\right)$ & $186(189)$ & $65.0(66.0)$ \\
\hline $1 \times 10^{-5}$ & $49 \times 10^{-7}\left(51 \times 10^{-7}\right)$ & $51 \times 10^{-7}\left(49 \times 10^{-7}\right)$ & $\underline{104}(\underline{100})$ & $\underline{51.0}(\underline{49.0})$ \\
\hline \multicolumn{5}{|c|}{ (B) Results obtained using radiotracer method } \\
\hline $36 \times 10^{-3}$ & $2 \times 10^{-2}$ & 1.6 & 80 & 44.4 \\
\hline $36 \times 10^{-4}$ & $18 \times 10^{-4}$ & $18 \times 10^{-2}$ & 100 & 50.0 \\
\hline $36 \times 10^{-5}$ & $17 \times 10^{-5}$ & $19 \times 10^{-3}$ & 112 & 52.8 \\
\hline $36 \times 10^{-6}$ & $17 \times 10^{-6}$ & $19 \times 10^{-4}$ & 112 & 52.8 \\
\hline
\end{tabular}

The values in the parentheses indicate results obtained using ligand TAAH. [C $]^{\circ}$ is the initial concentration of Co(II) ions (meq/ml) used in the sorption experiment. $\left[C_{\mathrm{s}}\right]$ is the equilibrium concentration of $\mathrm{Co}(\mathrm{II})$ ions on the solid phase $(\mathrm{mmol} / \mathrm{g})$ at the end of the sorption experiment. $\left[C_{\mathrm{L}}\right]$ is the equilibrium concentration of $\mathrm{Co}$ (II) ions on the liquid phase $(\mathrm{mmol} / \mathrm{ml})$ after the sorption experiment. $R_{\mathrm{d}}$ is the distribution ratio of $\mathrm{Co}$ (II) ions between the solid and liquid phase. 
where $V$ : volume of solution $(\mathrm{ml}), W_{\mathrm{s}}$ : weight of the solid material $(\mathrm{g}), A^{\mathrm{o}}$ : initial count rate of solution added for sorption (cps) $/ \mathrm{ml}, A_{\mathrm{L}}$ : count rate of solution after sorption (cps) $/ \mathrm{ml}$.

In the spectrophotometric determination of $R_{\mathrm{d}}$, the concentration of $\mathrm{Co}(\mathrm{II})$ in solution after sorption was calculated using Beer's law. The concentration of Co(II) on the clay was then calculated as follows:

$\left[C_{\mathrm{s}}\right]=[C]^{\mathrm{o}}-\left[C_{\mathrm{L}}\right]$

here, $[C]^{\circ}$ is the initial concentration of $\mathrm{Co}(\mathrm{II})(\mathrm{mmol} /$ $\mathrm{ml})$, and $\left[C_{\mathrm{L}}\right]$ is the concentration of $\mathrm{Co}(\mathrm{II})(\mathrm{mmol} / \mathrm{ml})$ after sorption experiment. The $R_{\mathrm{d}}$ values calculated using both spectrophotometric and radiotracer methods are given in Tables 6 and 7, together with the values of percentage sorption used to illustrate the effectiveness of retardation of $\mathrm{Co}$ (II) by each clay. The data listed in Tables 6 and 7 show a good agreement between the values of $R_{\mathrm{d}}$ and \% sorption obtained from the spectrophotometric and radiotracer methods for the sorption of $\mathrm{Co}^{2+}$ ions on bentonite and kaolinite. A deviation is clearly seen for the most dilute $\mathrm{Co}(\mathrm{II})$ samples (under-lined values in Tables 6 and 7), initial concentration $=1.0 \times 10^{-5} \mathrm{M}$. This is probably due to the limitation of Beer's law validity at very low concentrations. The results obtained show that bentonite is more effective than kaolinite in retardation of $\mathrm{Co}^{2+}$. Comparison between the results listed in Tables 6 and 7 indicate that, the effectiveness of bentonite and kaolinite in retardation of $\mathrm{Co}^{2+}$ decreases with increasing $\mathrm{Co}^{2+}$ concentration.

\section{Conclusion}

A method has been developed for the spectrophotometric determination of cobalt(II) using TA and TAAH as chromogenic reagents. The method was applied to the determination of cobalt(II) in authentic samples and then used for the spectrophotometric determination of the distribution ratio of cobalt on bentonite and kaolinite. The method has several advantages mainly, the reagents are easily synthesized and purified, large amounts of reagent in the sample solution do not interfere. The method has good selectivity and high sensitivity [the molar absorptivities and Sandell sensitivities values are $2.0456 \times 10^{4} 1 \mathrm{~mol}^{-1} \mathrm{~cm}^{-1}$ and 2.881 $\times 10^{-3}\left(\mathrm{~g} \mathrm{~cm}^{-2}\right)$ for TA and $1.8565 \times 10^{4} 1 \mathrm{~mol}^{-1} \mathrm{~cm}^{-1}$ and $3.1741 \times 10^{-3}\left(\mathrm{~g} \mathrm{~cm}^{-2}\right)$ for TAAH], it is also simple that the measurement can be carried out in aqueous solutions containing $40 \%$ ethanol without extraction or pretreatment of the sample in presence of small amounts of foreign ions which do interfere or large amounts of foreign ions that do not interfere. Co(II)-TAAP system is not effective in the spectrophotometric microdetermi- nation of $\mathrm{Co}(\mathrm{II})$ due to its low molar absorptivity $\left(0.1349 \times 10^{4} 1 \mathrm{~mol}^{-1} \mathrm{~cm}^{-1}\right)$.

\section{References}

[1] Uehara N, Fukuda K, Shijo Y. Jap Soc Anal Chem 1980;14:343.

[2] Issa RM, Ghoneim AK, Deifallah EM, Moustafa MM. J Indian Chem Soc 1994;71:561.

[3] Thakur M, Deb MK. Talanta 1999;49:561.

[4] Mohamed GG, Zayed MA, El-Gamel NEA. Spectrosc Lett 2000;33:821.

[5] El-Hefnawy GB, El-Borai MA, Aly EA, Gabr AA. Indian J Fibre Text Res 1992;17:160.

[6] Moreda W, Forrester AR. Tetrahedron 1997;53:12595.

[7] Geoffrey H, Jae-Hong C. Dyes Pigments 1999;42:249.

[8] Ogul'chansky TY, Yashchuk VM, Losytskyy MY, Kocheshev IO, Yarmoluk SM. Spectrochimica Acta Part A 2000;56:805.

[9] Madkour LH, El-Morsi MA, Ghonium MM. Monatshefte für Chemie 1995;126:1087.

[10] Barrera B, Gonzalez JFV, Martinez FB. Analyst 1985;110:811.

[11] Asuero AG, Rosales D, Rodrguez MM. Analyst 1982;107:1065.

[12] Navas MJ, Asuero AC, Rosales D. Microchem J 1986;33:331.

[13] Asuero AC, Marques ML, Navas MJ. Microchemistry 1987;36:216.

[14] Al-Nuri MA, Abu-Eid M, Zatar NA, Khalaf S, Hannoun M. Anal Chim Acta 1992;175:259.

[15] Giovanetti R, Bartocci V, Ferraro S, Gusteri M, Passamonti P. Talanta 1995;42:1913.

[16] Rodriguez AMG, de Torres AG, Pavon JMC, Ojeda CB. Talanta 1998;47:463.

[17] Furukawa M. Anal Chim Acta 1982;140:281.

[18] Katami T, Hayakawa T, Furukawa M, Shibata S. Analyst 1983;108:864.

[19] Katami T, Hayakawa T, Furukawa M, Shibata S. Analyst 1985;110:399.

[20] Parkash R, Bansal R, Rehani SK, Dixit S. Talanta 1998;46:1573.

[21] Park C, Cha K. Talanta 1998;46:1515.

[22] Shahwan T, Erten HN. Radioanal Nucl Chem 1999;1:151.

[23] Shahwan T, Erten H.N. Ph. D. thesis, Bilkent University, Bilkent, Ankara, Turkey; 2000.

[24] Amer SA, Gaber M, Issa RM. Polyhedron 1988;24:2635.

[25] Saw HM. J Am Soc 1979;101:154.

[26] Frank JW. The Analytical Uses of Ethylenediaminetetraaceticacid. Princeton Newjersey, Toronto, London, New York: D. Van Nostrand Co. Inc.; 1965.

[27] Britton HTS. Hydrogen ions, vol. L. 2nd ed. London: Longmans; 1952.

[28] Abdel-Kader MH, Issa RM, Abousekkina MM, Assar SS. Delta J Sci 1987;11:171.

[29] Ingle JD, Crouch SR. Spectrochemical analysis. Englewood Cliffs, New Jersey: Prentice-Hall, Inc.; 1988.

[30] Kemp W. Organic spectroscopy. London: The Macmillan Press Ltd.; 1975.

[31] Dessouki HA, Gaber M, El-Ansary AL. Egypt J Chem 1989;32:639.

[32] Mahmoud MR, Ibrahim SA, Hamed MA. Spectrochim Acta Part A 1983;39:729.

[33] Hofer E, Hufimann H. Tetrahedron Lett 1971;35:3241.

[34] Ibrahim SA, Hammam AM, Kamal El-Dean AM, Mohamed AA, Rageh NM. Canadian J Appl Spec 1993;1:38.

[35] Abdel-Mawgoud AM, Hamed MM, Mostafa HM. Monatshefte für Chemie 1997;128:553.

[36] Mignel W, Charette JJ, De Hoffman E. J Am Chem Soc 1966;88:3808.

[37] Pimentel GC. J Am Chem Soc 1957;79:3323. 
[38] Issa RM. Egypt J Chem 1971;14:133.

[39] Issa RM, Maghrabi JY. Z Physik Chem (Leipzig) 1975;56:1120.

[40] Zayan SE, Issa RM, El-Dessouky MA, Eskander MF. Z Physik Chem (Leipzig) 1966;233:313.

[41] Babko A, Philipenko A. Photometric analysis, general principles and working tools. Moscow: Ed. Mir. Publisher; 1971.
[42] Jop P. Ann Chim 1928;9:113.

[43] Yoe JH, Jones AL. Ind Eng Chem Anal 1944;16:111.

[44] Issa RM. Egypt J Chem 1972;15:417; 1975;1:18; Z Physik Chem (Frankfurt) 1972;117:251; Z Physik Chem (Leipzig) 1973; 253:289.

[45] Ringbom A. Z Anal Chem 1939;115:332. 